\title{
Projeto de trabalho aplicado ao ensino de eficiência energética em um curso técnico
}

\author{
Work project applied to teaching energy efficiency in a technical \\ course
}

\section{Proyecto de obra aplicado a la enseñanza de la eficiencia energética en un curso técnico}

Rhasla Ramos Abrão Wanderley ${ }^{1}$; Marilyn Aparecida Errobidarte de Matos²

\section{RESUMO}

As metodologias ativas têm sido utilizadas com mais frequência nas diversas áreas do conhecimento. Em consonância a essa perspectiva, este artigo tem como objetivo apresentar os resultados da aplicação da metodologia "Projetos de Trabalho", de Fernando Hernández (1998), na disciplina de eficiência energética do curso técnico de nível médio integrado em Eletrotécnica do IFMS, campus Campo Grande, e verificar sua viabilidade no processo de ensino-aprendizagem nesta modalidade de ensino. Como forma de avaliar a aprendizagem dos estudantes foram utilizados Mapa Conceituais e um questionário visando um feedback em relação a metodologia aplicada. Os estudantes construíram mapas conceituais antes e depois do desenvolvimento da atividade proposta, e foi possível identificar grande enriquecimento de conceitos, e de uma forma mais prática, mais interativa e menos engessada, além de desenvolver habilidades comportamentais que o mundo do trabalho exige.

Palavras-chave: Metodologia ativa; Ensino-aprendizagem; Mapa conceitual.

\begin{abstract}
Active methodologies have been used more frequently in various areas of knowledge. In line with this perspective, this paper aims to present the results of the application of Fernando Hernández "Work Projects" methodology in the energy efficiency discipline of IFMS's Electrotechnical Integrated High School, Campo Grande campus, and to verify its viability in the teaching- learning process in this teaching modality. As a way of evaluating students' learning, the Concept Map methodology and a questionnaire were applied aiming to have positive or negative feedback regarding the applied methodology. Students built concept maps before and after the development of the proposed activity, and it was possible to identify great enrichment of concepts, and in a more practical, more interactive and less plaster, as well as developing behavioral skills that the working world demands.
\end{abstract}

Keywords: Active Methodology; Teaching-learning; Conceitual map.

\section{RESUMEN}

Las metodologías activas se han utilizado con mayor frecuencia en diferentes áreas del conocimiento. En línea con esta perspectiva, este artículo tiene como objetivo presentar los resultados de la aplicación de la metodología "Proyectos de obra", de Fernando Hernández (1998), en la disciplina de eficiencia energética del

\footnotetext{
${ }^{1}$ Doutora em Engenharia Elétrica e Professora do Instituto Federal de Educação, Ciência e Tecnologia de Mato Grosso do Sul (IFMS), Campo Grande/MS - Brasil. E-mail: rhasla.abrao@ifms.edu.br

${ }^{2}$ Doutora em Meio Ambiente e Desenvolvimento Regional e Professora Titular de Metodologia da Pesquisa do Instituto Federal de Educação, Ciência e Tecnologia de Mato Grosso do Sul (IFMS), Campo Grande/MS - Brasil. E-mail: marilyn.matos@ifms.edu.br
} 
curso técnico integrado en Electrotecnia en IFMS, campus Campo Grande, y verificar su viabilidad en el proceso de enseñanza-aprendizaje en esta modalidad de enseñanza. Como forma de evaluar el aprendizaje de los estudiantes, se utilizaron mapas conceptuales y un cuestionario para retroalimentar la metodología aplicada. Los estudiantes construyeron mapas conceptuales antes y después del desarrollo de la actividad propuesta, y fue posible identificar un gran enriquecimiento de conceptos, y de una manera más práctica, más interactiva y menos enlucida, además de desarrollar habilidades conductuales que el mundo laboral requiere.

Palabras clave: Metodología activa; Enseñanza-aprendizaje; Mapa conceptual.

\section{INTRODUÇÃO}

O Instituto Federal de Educação, Ciência e Tecnologia de Mato Grosso do Sul (IFMS) foi criado pela Lei no 11.892, de 29 dezembro de 2008, quando o Ministério da Educação (MEC) reestruturou a Rede Federal de Educação Profissional, Científica e Tecnológica (IFMSa, 2019, p.1).

O primeiro campus do IFMS a entrar em funcionamento foi Nova Andradina, em 2010. No ano seguinte, outros seis campi, Aquidauana, Campo Grande, Corumbá, Jardim, Ponta Porã e Três Lagoas, entraram em operação, inicialmente em sede provisória e em parceria com o Instituto Federal do Paraná (IFPR).

Desde o início das atividades, o índice de reprovação e evasão de estudantes do campus Campo Grande do IFMS é alto. Como medida para amenizar esses problemas, o IFMS conta com as comissões locais que fazem cumprir o Programa de Permanência e Êxito do IFMS, uma estratégia institucional de planejamento, execução e avaliação das ações e atividades que assegurem as condições de permanência e êxito dos estudantes matriculados no IFMS.

A Comissão de Permanência e Êxito do campus Campo Grande em levantamento dos principais fatores que influenciam nesses índices citam, entre outros, a falta de seleção na admissão dos estudantes, falta de infraestrutura para as aulas práticas, possibilidade de reprovação, falta de interesse dos estudantes nas áreas dos cursos técnicos ofertados, diferença na estrutura curricular entre o ensino técnico e o propedêutico e falta de informação e divulgação sobre a proposta pedagógica dos Institutos Federais.

O IFMS tem como missão "promover a educação de excelência por meio do ensino, pesquisa e extensão nas diversas áreas do conhecimento técnico e tecnológico, formando profissional humanista e inovador, com vistas a induzir o desenvolvimento econômico e social local, regional e nacional" (IFMSb, 2019, p. 1). E, para isso, possui alguns programas que norteiam ações em busca da qualidade e inovação, sempre em prol da comunidade.

Percebe-se que o mundo tem caminhado para a $4^{a}$ Revolução Industrial, no qual a Internet das Coisas (IoT) e a Inteligência Artificial (IA) irão dominar o mundo das tecnologias. E, segundo Bacich e Moran (2018, p. 160), "os estudantes do século XXI, têm tido um comportamento diferente em sala de aula, em parte, graças ao uso das tecnologias digitais de informação e comunicação (TDIC)". Com inúmeras possibilidades de acesso a entretenimentos que existem hoje, como a internet, séries, filmes e redes sociais, os docentes buscam criar e aplicar diferentes metodologias de ensino para que os estudantes sejam os protagonistas no processo de ensino-aprendizagem e desenvolvam habilidades específicas que o mundo do trabalho exige.

Diante disso, percebe-se a necessidade de mudanças na educação e formação de cidadãos em todas as áreas, inclusive na área das ciências exatas e engenharias. $\mathrm{E}$ as metodologias ativas são cada vez 
mais empregadas nas salas de aulas para atender às novas demandas de educação da geração digital (BENTO; NETO; OLIVEIRA, 2017), como o uso da gamificação, sala de aula invertida, aprendizagem baseada em problemas, aprendizagem baseada em projetos e método de caso. Elas constituem alternativas pedagógicas que colocam o foco do processo de ensino e de aprendizagem no aprendiz, envolvendo-o na descoberta, investigação ou resolução de problemas.

Um exemplo de sucesso de aplicação de metodologia ativa é o trabalho de Silva et al. (2019), que aplicaram a metodologia de gamificação no ensino de física. Os resultados mostraram que os alunos que tiveram aulas gamificadas obtiveram um ganho de aprendizagem $(\mathrm{g}=0,38)$ superior aos alunos que tiveram aulas tradicionais $(g=0,11)$. Este é um método que também se enquadra em cursos da área de exatas, e em curso de nível médio profissionalizante.

Inclusive, o Conselho Nacional de Educação (CNE), por meio da Resolução no 2, de 24 de abril de 2019 alterou as diretrizes curriculares nacionais do curso de graduação em engenharia, com o objetivo de integrar mais a teoria com a prática, trazer inovação, empreendedorismo e flexibilidade às formações da área, visando melhorar a competitividade do país, a empregabilidade de egressos e desenvolver não só competências técnicas como também habilidades comportamentais valorizadas pelo mercado (BRASIL, 2019).

Percebe-se, também, a necessidade de formação continuada para os professores que trabalham com esses jovens da era digital e com os cursos técnicos de nível médio, pois a formação dos docentes que ministram as disciplinas técnicas, em boa parte, é o bacharelado, não sendo eficiente para tratar de um currículo integrado. Para Silva e Santos (2020, p.2) "a formação continuada configura-se como um processo com conotação de evolução e continuidade, valorizada em virtude dos múltiplos e novos desafios do mundo contemporâneo que solicita dos professores novas práticas para a construção de conhecimentos".

Diante das necessidades e desafios citados, este artigo tem como objetivo apresentar os resultados da aplicação da metodologia "Projetos de Trabalho", de Fernando Hernández (1998), na disciplina de eficiência energética do curso técnico de nível médio integrado em Eletrotécnica do IFMS, campus Campo Grande, e verificar sua viabilidade no processo de ensino-aprendizagem nessa modalidade de ensino.

Atualmente, os cursos do campus Campo Grande, na maior parte de suas disciplinas técnicas, utilizam o método tradicional de aula, com o professor como protagonista do sistema de ensino-aprendizagem, aulas expositivas e métodos de avaliação também tradicionais.

Além disso, é um enorme desafio para o professor conseguir adequar as técnicas de metodologias ativas aos conteúdos curriculares já propostos nas ementas dos projetos de curso, bem como implementá-las em salas de aulas com grande número de estudantes, como no caso do IFMS.

\section{FUNDAMENTAÇÃO TEÓRICA}

Através da Pirâmide de Aprendizagem da NTL (National Training Laboratories), percebe-se que quanto mais o indivíduo interage, compartilha informações, dialoga, como nos grupos de discussão, maior a probabilidade de o novo conhecimento ficar retido na estrutura cognitiva, representado de maneira didática na Figura 1. 
Figura 1 - Pirâmide de Estudo da NTL (National Training Laboratories).

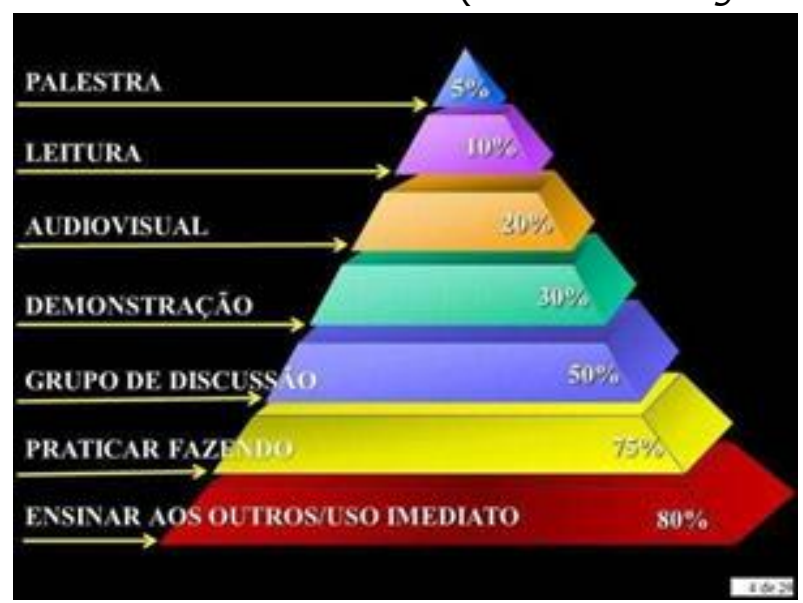

Fonte: Coelho, 2013

Segundo o professor Alécio (COELHO, 2013), é importante que cada instituição encontre seu modelo de ensino, pois o que funciona em uma não necessariamente se aplicará bem em outra. Além disso, é necessário adequar os mecanismos de avaliação às novas metodologias.

De acordo com o Bacich (2018), "nunca se falou tanto em inovar processos educacionais, rever práticas, formar professores para uma educação transformadora e considerar os estudantes como protagonistas", no entanto, há muito tempo, a pedagogia do fazer, de colocar o estudante como protagonista do seu aprendizado e diante de uma educação ativa, vem sendo promulgada,

No início do século passado, John Dewey concebeu e colocou em prática a educação baseada no processo ativo de busca do conhecimento pelo estudante, que deveria exercer sua liberdade. Para Dewey, a educação deveria formar cidadãos competentes e criativos, capazes de gerenciar sua própria liberdade. Sua proposta era a de que a aprendizagem ocorresse pela ação, o learning by doing, ou aprender fazendo, handson. (VALENTE, 2019, p. 101).

Conforme Bacich e Moran (2018), as metodologias ativas têm sido implementadas por meio de diversas estratégias, como a aprendizagem baseada em projetos (project-based learning - PBL); a aprendizagem por meio de jogos (game-based learning - GBL); o método do caso ou discussão e solução de casos (teaching case); e a aprendizagem em equipe (team- based learning - TBL).

A aprendizagem baseada em projetos ( $A B P$ ) ou project-based learning ( $P B L$ ), tem tido grande aproveitamento em diferentes áreas e disciplinas. Este método pode ser aplicado nas disciplinas técnicas do curso de eletrotécnica, pois estimula os estudantes a buscarem soluções para resolver problemas reais.

Na tentativa de minimizar as lacunas entre as exigências do mercado de trabalho e a formação em engenharia, a metodologia da Aprendizagem Baseada em Problemas ou Problem Based learning (PBL) tem sido utilizada como uma estratégia para aproximar os estudantes de engenharia da realidade por meio de atividades que permitem a aplicação prática de conteúdos teóricos na resolução de problemas que partem da própria percepção dos estudantes (RIBEIRO, 2008).

$\mathrm{Na}$ abordagem da sala de aula invertida (Flipped Classroom), o aluno estuda previamente, e a aula torna-se o lugar de aprendizagem ativa, onde há perguntas, discussões e da globalização entendida como um processo muito mais interno do que externo, no qual as relações entre conteúdos e áreas 
de conhecimento têm lugar em função das necessidades que traz consigo o fato de resolver uma série de problemas que subjazem na aprendizagem (HERNÁNDEZ; VENTURA, 1998).

\begin{abstract}
Na pedagogia de projetos o aluno aprende no processo de produzir, de questionar, de levantar dúvidas, de pesquisar e (re)criar relações, que incentivam novas buscas, descobertas, compreensões e (re)construções do conhecimento. E, portanto, o papel do docente deixa de ser o de transmitir informações - que tem como centro a atuação do professor -, para criar situações de aprendizagens cujo foco se incide sobre as relações que se estabelecem nesse processo, cabendo ao professor realizar mediações necessárias para que o aluno consiga encontrar sentido, significado naquilo que está aprendendo, a partir das relações criadas nessas situações. (PRADO, 2005, p. 6).
\end{abstract}

Sena e Finatti (2011, p. 2468) afirmam que "os Projetos de Trabalho buscam o conhecimento como um todo, já que as áreas do conhecimento são correlacionadas e o ser humano aprende de forma global. A compartimentalização do conhecimento em disciplinas específicas é substituída por grandes temas que abarcam os saberes como um todo". E ainda, "visa favorecer a aprendizagem, a formação da autonomia do aluno, além de sua formação crítica e reflexiva, sem perder de vista os conteúdos fundamentais contextualizados na prática social do educando e a função social da escola".

De acordo com Hernández (2000), os projetos de trabalho têm os seguintes pontos em comum com outras estratégias de ensino:

a) Vão além dos limites curriculares (tanto das áreas como dos conteúdos);

b) Implicam a realização de atividades práticas;

c) Os temas selecionados são apropriados aos interesses e ao estágio de desenvolvimento dos estudantes;

d) Realizam-se experiências de primeira mão;

e) Deve ser feito algum tipo de pesquisa;

f) É necessário trabalhar estratégias de busca, organização e estudo de diferentes fontes de informação;

g) Implicam atividades individuais, grupais e de classe, em relação às diferentes habilidades e conceitos que são aprendidos.

Nessa forma de conceber a educação, os estudantes participam de um processo de pesquisa, que tem sentido para eles, e utilizam diferentes estratégias de pesquisa; podem participar do processo de planejamento da própria aprendizagem, e, Ihes auxilia a serem flexíveis, reconhecer o "outro" e compreender seu próprio meio pessoal e cultural (HERNÁNDEZ, 2000, p.183).

Uma das formas de avaliar a aprendizagem significativa dos estudantes são os mapas conceituais, desenvolvidos em 1972 por Novak na Universidade de Cornell, através dos quais buscou acompanhar e entender as mudanças na maneira como as crianças compreendiam a ciência (NOVAK; CANAS, 2010).

Segundo Novak e Canas (2010), mapas conceituais são ferramentas gráficas para a organização e representação do conhecimento, com um conjunto de características para representar as ligações entre as informações, considerando uma "ordem hierárquica, com os conceitos mais inclusivos e gerais no topo e os mais específicos e menos gerais dispostos hierarquicamente abaixo". Os autores 
afirmam ainda que "essa estrutura de conhecimento de um determinado aprendiz é também chamada de estrutura cognitiva do indivíduo".

\section{METODOLOGIA}

A metodologia aplicada neste estudo compreendeu o estudo de caso, fundamentada em Projetos de Trabalho, abordada no livro do autor Fernando Hernández "A Organização do Currículo por Projetos de Trabalho" de 1998. O conteúdo escolhido foi "Fontes Renováveis de Energia" ministrado na disciplina de Eficiência Energética, com carga horária de três horas-aula por semana em uma turma com 21 alunos do último semestre do curso técnico de nível médio integrado em Eletrotécnica, o qual tem duração de três anos e meio.

Seguiu-se os passos da Elaboração do Projeto de Trabalho e a descrição das etapas da proposta, segundo Hernández (1998):

1) A escolha do tema: O tema Fontes Renováveis de Energia foi definido pela professora da disciplina Eficiência Energética. Este tema foi escolhido por ser muito teórico em relação aos outros conteúdos da área técnica do curso e a ideia de utilizar a metodologia "Projeto de trabalho" é deixá-lo mais dinâmico.

2) A atividade docente - foi solicitado aos estudantes que explicitassem em forma de mapa conceitual os conhecimentos sobre o tema para a aplicação da metodologia. Feito isso, foram apresentados os passos que os estudantes deveriam seguir ao longo do período de um mês e meio, para o desenvolvimento do projeto.

3) A atividade proposta:

a) Passo 1: Os estudantes tiveram que se dividir em grupos e foi sorteada uma fonte renovável (solar, eólica, biomassa, maremotriz, hídrica, geotérmica) para cada grupo.

b) Passo 2: Realizaram uma pesquisa inicial sobre as fontes, baseada em algumas questões propostas pela professora, como por exemplo: princípio de funcionamento de geração com a fonte escolhida; legislação vigente; histórico no mundo e no Brasil; dentre outras informações e curiosidades.

c) Passo 3: Os grupos apresentaram uma ideia de maquete/projeto envolvendo conhecimentos de outras áreas do curso, como por exemplo, instalações elétricas, máquinas elétricas, eletrônica analógica e digital, para que a professora verificasse a viabilidade prática.

d) Passo 4: A partir da pesquisa realizada sobre as fontes renováveis, os estudantes elaboraram questões de múltipla escolha ou de verdadeiro/falso para utilizarem juntamente às maquetes. Assim, além da maquete tratar do subtema em sua construção e funcionamento, deveria validar as respostas às questões, como um jogo.

e) Passo 5: Após a avaliação da professora de todas as etapas anteriores, os grupos construíram e testaram seus projetos/maquetes, sempre com auxílio da professora e/ou de outros professores do curso e técnicos de laboratório.

f) Passo 6: Os grupos apresentaram as principais informações sobre suas fontes para todos da sala. 
De forma breve, explicaram o funcionamento do projeto/maquete (parte elétrica/eletrônica) e de como seria a interação dos demais colegas com seus projetos e como responderiam/validariam às questões/respostas.

g) Passo 7: Todos os estudantes tiveram que interagir com todos os outros trabalhos, enquanto a professora avaliava o aproveitamento e participação de cada estudante.

Durante todas as etapas os estudantes foram avaliados de forma individual e a professora realizou as correções parciais para que os projetos tivessem êxito no final.

Após o encerramento da atividade, foi aplicado um questionário (feedback da metodologia), com 10 perguntas subjetivas aos estudantes, a fim de levantar dados sobre a aceitabilidade da intervenção pedagógica e possíveis melhorias e a construção de um mapa conceitual sobre o tema, baseados nos conceitos abordados em Prado e Almeida (2009, p.163-172), com o intuito de verificar as mudanças conceituais nas estruturas cognitivas desses estudantes.

\section{RESULTADOS E DISCUSSÕES}

Os estudantes foram divididos em 6 grupos, de forma que cada um trabalhasse uma das fontes renováveis de energia (biomassa, hídrica, solar, eólica, geotérmica e marés). Todos os grupos construíram maquetes para explicar o princípio de funcionamento de cada tipo de geração de energia elétrica que utiliza fontes renováveis. E para a interação com as perguntas e respostas (elaboradas conforme passo 4), utilizaram materiais dos laboratórios do próprio curso de eletrotécnica.

Na Figura 2, tem-se o projeto de Biomassa, no qual os estudantes fizeram uma maquete para demonstrar o princípio de funcionamento de uma termoelétrica movida a biomassa, e para a parte de interação de perguntas e respostas sobre a biomassa, utilizaram conhecimento de eletricidade, eletrônica analógica e eletrônica digital, pois trabalharam com portas lógicas, protoboard, entre outros dispositivos eletrônicos.

Figura 2 - Projeto sobre biomassa

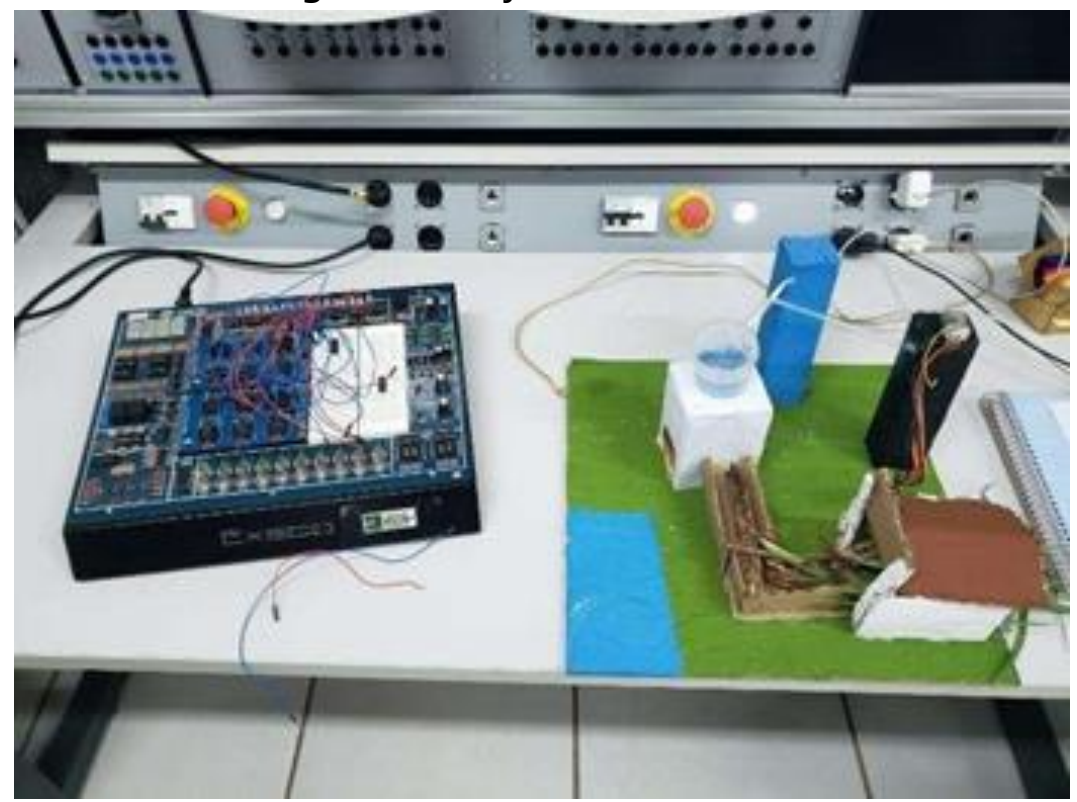

Fonte: Autora 
No projeto sobre Energia Eólica (Figura 3), o grupo construiu uma turbina com ventoinha de impressora, que funciona com o acionamento através da seleção das respostas corretas. As ligações do projeto envolveram conhecimentos de eletricidade, eletrônica analógica, eletrônica digital e máquinas elétricas.

Figura 3 - Projeto sobre Energia Eólica

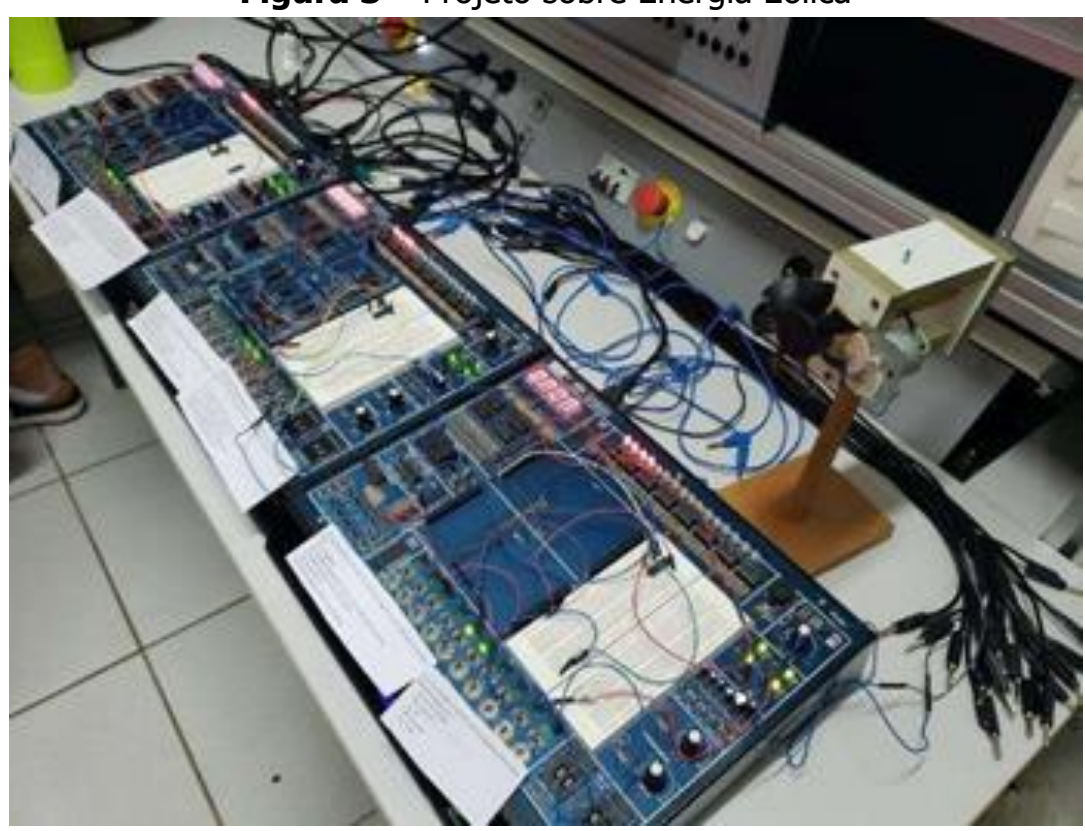

Fonte: Autora

Para o projeto sobre Maremotriz (Figura 4), os estudantes também utilizaram conhecimentos de eletricidade, eletrônica analógica, eletrônica digital e máquinas elétricas. Para a maquete utilizaram um isopor com água para representar o mar e simularam o braço do gerador de energia maremotriz, com fios de cobre e imã.

Figura 4 - Projeto sobre Maremotriz

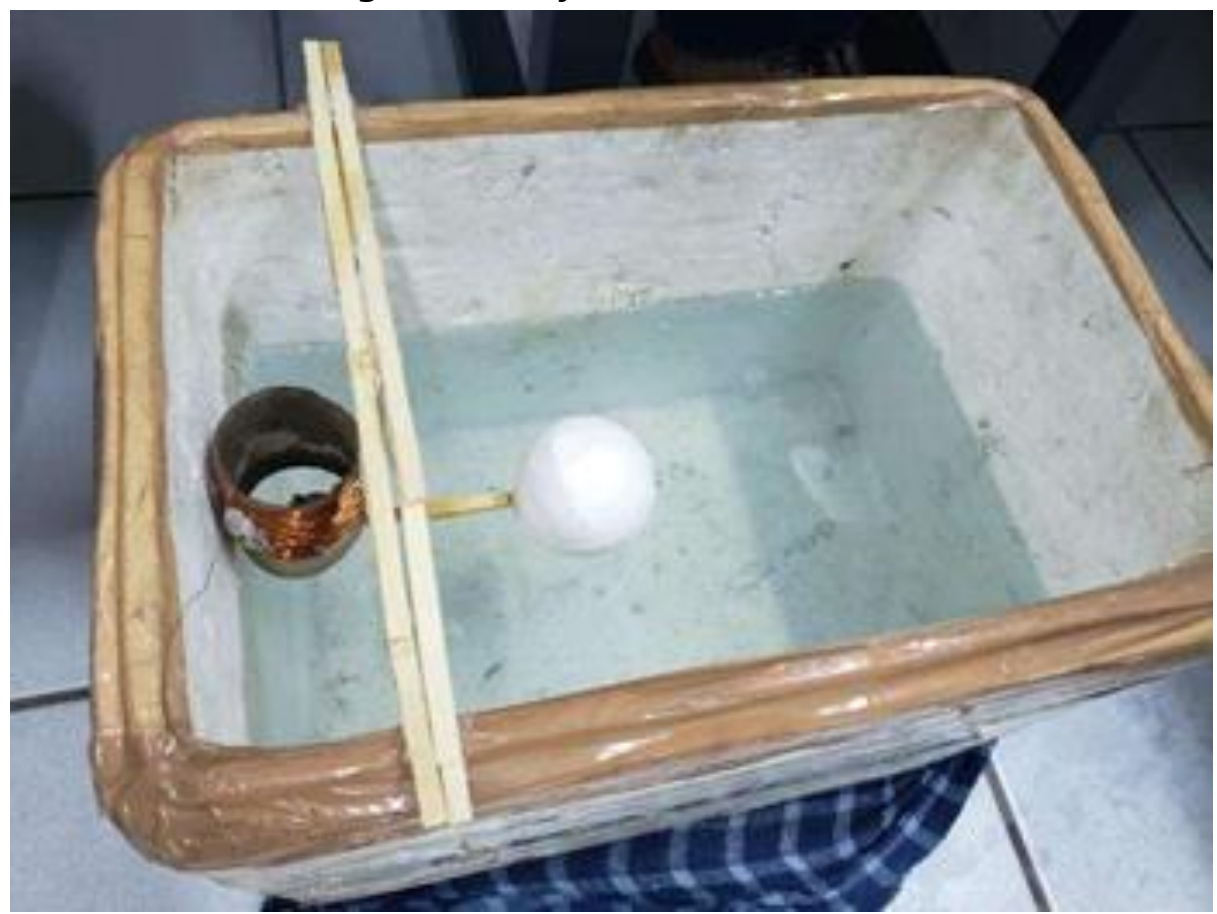

Fonte: Autora 
A confecção dos mapas conceituais se deu antes da aplicação da metodologia de projetos de trabalho para evidenciar os conhecimentos prévios dos estudantes e após terminadas todas as atividades para que houvesse a possibilidade de comparação dos mapas evidenciando as mudanças conceituais nas estruturas cognitivas dos estudantes.

As Figuras 5 e 6 apresentam, respectivamente, um exemplo do mapa conceitual (de um mesmo estudante) construído (no caderno) antes e outro depois do tema ter sido trabalhado.

Figura 5 - Mapa conceitual do "aluno x" antes da intervenção

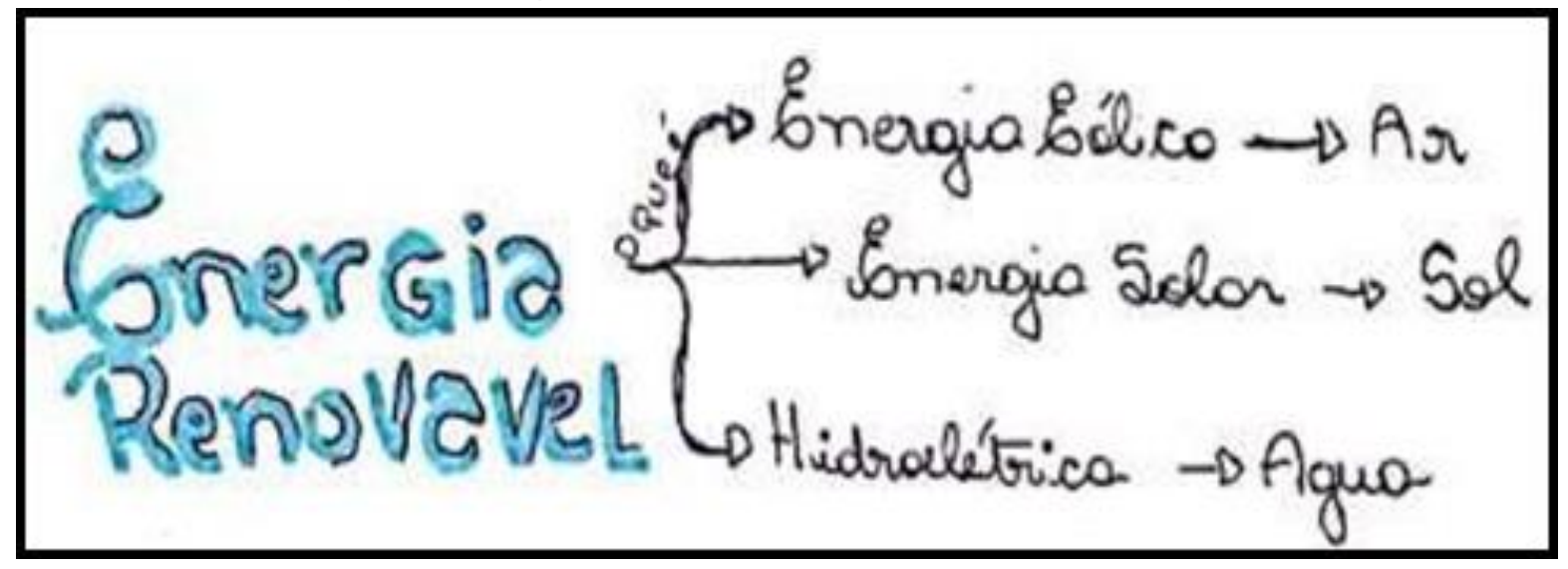

Fonte: Autora

Figura 6 - Mapa conceitual do "aluno x" após aplicação da intervenção

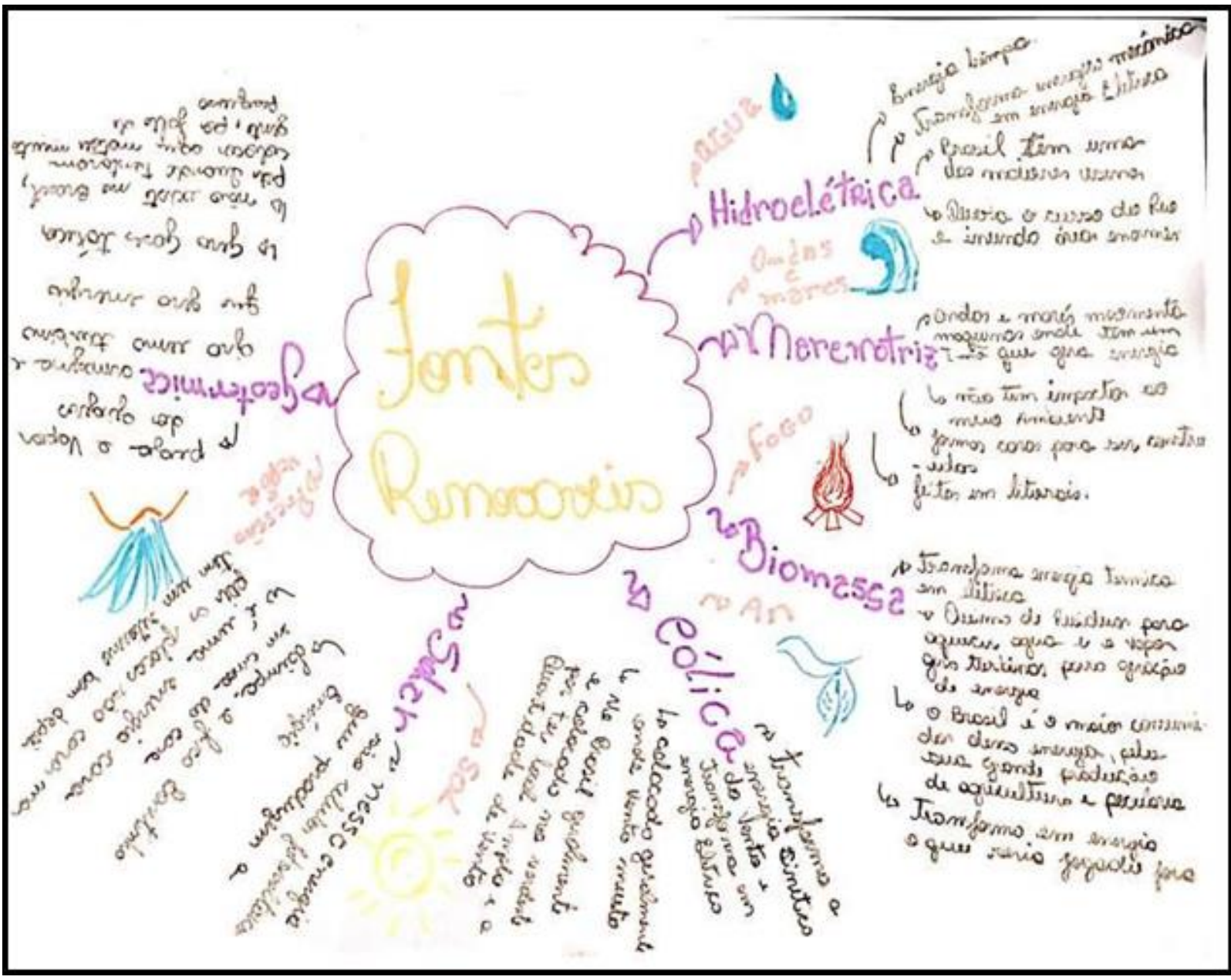

Fonte: Autora 
Figura 7 - Reescrita do mapa conceitual do "aluno x" antes da aplicação da intervenção

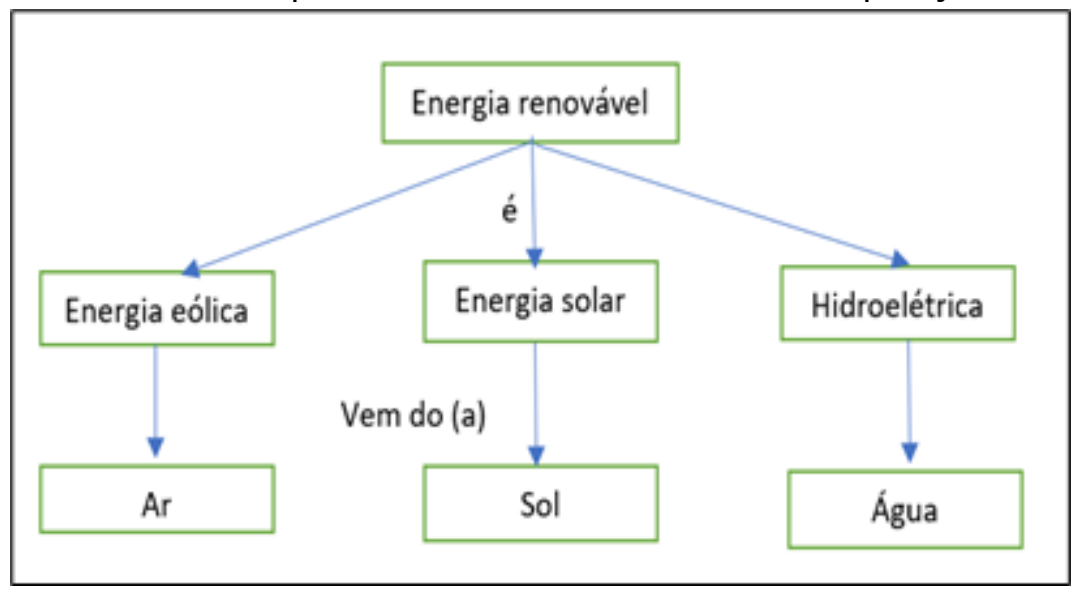

Fonte: Autora

Figura 8 - Reescrita do mapa conceitual do "aluno x" após aplicação da intervenção

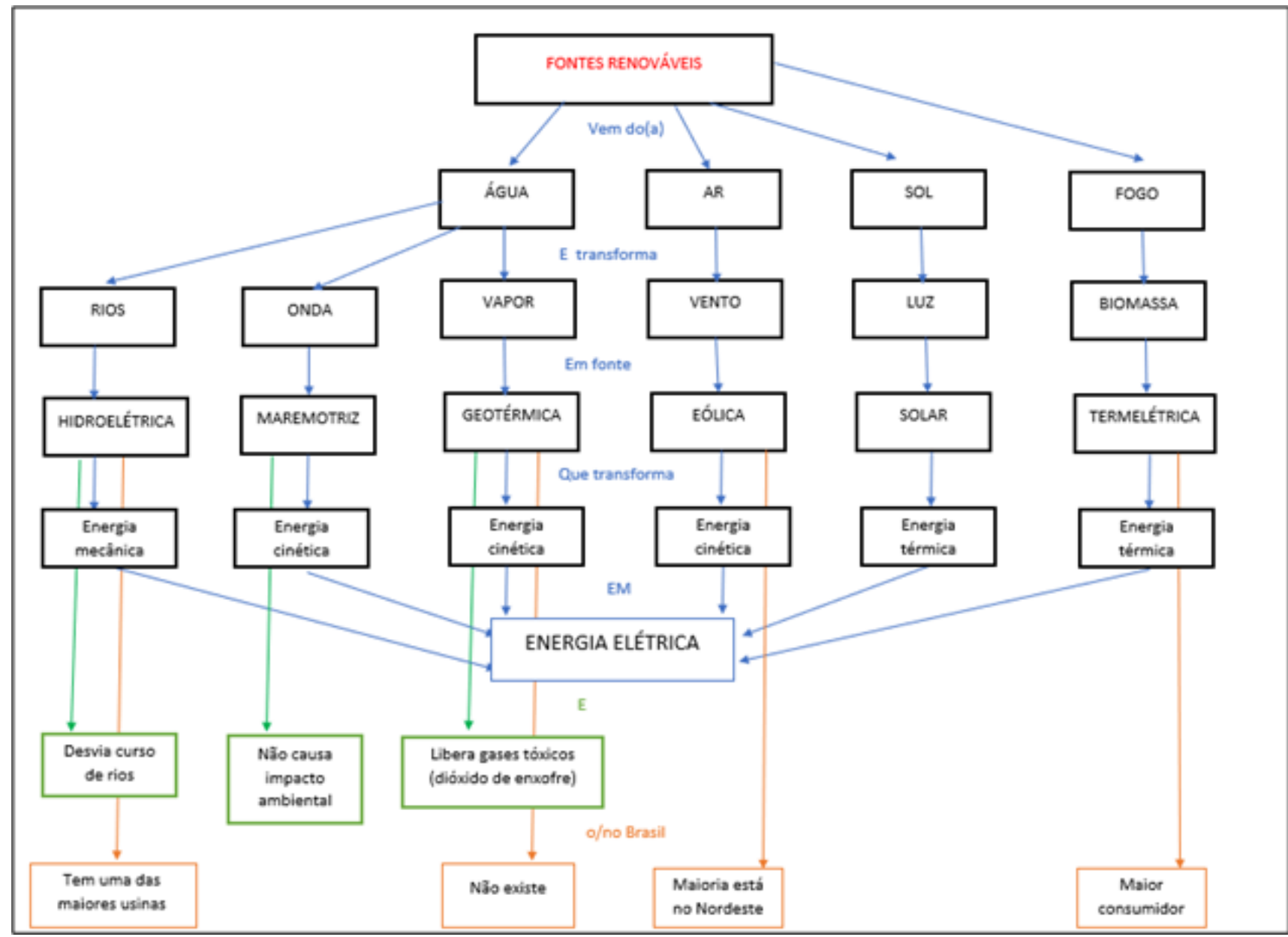

Fonte: Autora

Ao comparar os mapas conceituais (antes e depois) ficou evidente o enriquecimento de informações teóricas sobre o tema trabalhado. É importante ressaltar que os mapas conceituais foram construídos sem apoio de qualquer material didático, representando fielmente o que o estudante sabe sobre o tema.

Percebeu-se o aumento de conceitos e ligações entre eles, o que implica em mudanças significativas na aprendizagem. A construção dos mapas conceituais proporcionou aos estudantes liberdade para que explicitassem, no papel, a maneira como organizam as informações e racionalizam os conceitos 
em suas estruturas cognitivas sem a pressão de estar certo ou errado, pois segundo Novak e Canas (2010) não existe mapa conceitual certo ou errado.

Em todos os Mapas Conceituais construídos antes da aplicação da atividade, os estudantes descreveram apenas que existiam fontes renováveis e não renováveis de energia, e deram os exemplos mais conhecidos de cada uma - solar, hídrica, combustíveis fósseis - informando se eram fontes infinitas, poluentes ou não ao meio ambiente, como pode-se visualizar no Quadro 1.

Quadro 1 - Principais informações contidas nos mapas conceituais dos alunos antes de iniciar o projeto de trabalho

\begin{tabular}{|c|c|c|}
\hline Tipo de Informação & Informações & $\begin{array}{l}\text { Conceito: } \\
\text { Certo/Errado }\end{array}$ \\
\hline \multirow{2}{*}{$\begin{array}{l}\text { Tipos de Fontes ligadas a } \\
\text { Fontes Renováveis }\end{array}$} & $\begin{array}{l}\text { Energia Solar -> Sol } \\
\text { Energia Eólica -> Vento } \\
\text { Hidroelétrica -> Água }\end{array}$ & Certo \\
\hline & $\begin{array}{l}\text { Alguns colocaram nuclear e combustíveis } \\
\text { fósseis como fontes renováveis e } \\
\text { biomassa como não renovável }\end{array}$ & Errado \\
\hline Impactos & $\begin{array}{l}\text { "Contribuem para o meio ambiente" } \\
\text { "Pouco impacto ambiental" }\end{array}$ & Certo \\
\hline $\begin{array}{l}\text { Diferença entre Fontes } \\
\text { Renováveis e Não- } \\
\text { Renováveis }\end{array}$ & $\begin{array}{l}\text { Conseguiram informar que as renováveis são } \\
\text { infinitas e as não-renováveis são finitas; E } \\
\text { que as não-renováveis causam mais } \\
\text { impactos negativos ao meio ambiente. }\end{array}$ & Certo \\
\hline
\end{tabular}

Após o desenvolvimento das atividades, notou-se que os novos mapas conceituais "cresceram" em quantidade de ligações entre conceitos e diferenças conceituais - os estudantes conseguiram agregar muito mais informações sobre os tipos de fontes renováveis de energia, descrever os tipos, vantagens e desvantagens de cada uma, o princípio de funcionamento de geração de cada fonte, quais são encontradas no Brasil, países que mais utilizam cada tipo de fonte, os principais impactos de cada uma e as fontes que tem incentivo no Brasil.

Identificando alguns equívocos de informações conceituais/técnicas, como por exemplo sobre as conversões de energia nos processos de geração de energia elétrica a partir das fontes renováveis trabalhadas (caso do "aluno $x^{\prime \prime}$ ), a professora retomou a discussão, relacionou os principais equívocos e, então, realizou a correção para todos em sala de aula.

Quadro 2 - Principais informações contidas nos mapas conceituais dos alunos depois do projeto de trabalho

\begin{tabular}{|c|c|}
\hline Tipo de Informação & Informações \\
\hline $\begin{array}{c}\text { Tipos de Fontes ligadas a } \\
\text { Fontes Renováveis }\end{array}$ & $\begin{array}{c}\text { Solar Eólica } \\
\text { Hidroelétrica Biomassa } \\
\text { Maremotriz Geotérmica }\end{array}$ \\
\hline $\begin{array}{c}\text { Princípio de } \\
\text { funcionamento }\end{array}$ & Informaram a matéria-prima e a tecnologia associada a cada tipo de \\
geração
\end{tabular}




\begin{tabular}{|c|c|}
\hline Impactos & $\begin{array}{c}\text { Solar: não possui impacto significativo ao meio ambiente; } \\
\text { Eólica: incomoda os pássaros; } \\
\text { Hidroelétrica: alagamento de grandes áreas, impacto na fauna, flora e } \\
\text { ribeirinhos; } \\
\text { Biomassa: usada em termoelétricas, geram CO2 com a queima. } \\
\text { Maremotriz: Baixo impacto à vida marítima; } \\
\text { Geotérmica: riscos de explosão e inalação do gás tóxico presente } \\
\text { no interior da terra, caso não sejam adotadas todas as medidas de } \\
\text { segurança indicadas para este tipo de geração. }\end{array}$ \\
\hline $\begin{array}{l}\text { Países que mais utilizam } \\
\text { cada fonte }\end{array}$ & $\begin{array}{c}\text { Solar: China, Japão, Alemanha Eólica: China, } \\
\text { EUA, Alemanha Hídrica: EUA, China, Índia, Brasil } \\
\text { Biomassa: Brasil, China, Suécia } \\
\text { Marés: Japão, França, Coreia do Sul, Inglaterra, EUA Geotérmica: Estados } \\
\text { Unidos, Filipinas, Indonésia }\end{array}$ \\
\hline $\begin{array}{l}\text { Fontes mais utilizadas no } \\
\text { Brasil }\end{array}$ & Hídrica e Biomassa \\
\hline Informações diversas & Curiosidades, legislação. \\
\hline
\end{tabular}

Fonte: Autora (2019)

Além do envolvimento de diversas disciplinas técnicas do curso de eletrotécnica, observadas pela professora durante as apresentações dos projetos, uma das perguntas do questionário (feedback da metodologia) era sobre as disciplinas envolvidas. Nas respostas, desse questionário, os estudantes citaram que tiveram que relembrar conhecimentos de outras disciplinas não identificadas na maquete dos projetos, mas que foram necessários para entenderam alguns conceitos, e conseguirem explicar o princípio de funcionamento da geração de energia, como por exemplo, disciplinas de física, química e biologia. Com isso pode-se perceber um currículo transdisciplinar, característica dos cursos integrados. E, ainda, dois grupos buscaram conhecimentos extras como programação de Arduino.

Com a aplicação do questionário, $85 \%$ dos estudantes afirmaram ter gostado mais de trabalhar com projetos que da forma tradicional. Os $15 \%$ que preferiram o método tradicional justificaram com a falta de tempo, por estarem no último semestre e terem que cumprir o estágio obrigatório e o Trabalho de Conclusão de Curso (TCC) considerando mais fácil e rápido estudar para prova, ao invés de pesquisar e resolver o desafio de construir uma maquete multidisciplinar na área de eletrotécnica.

\section{CONCLUSÃO}

Com a metodologia "Projeto de Trabalho" de Fernando Hernández (1998), foi possível trabalhar de forma mais prática e eficaz com um tema que normalmente tem uma abordagem apenas teórica, onde o professor é o centro/protagonista na sala de aula e utiliza a exposição oral de conteúdos, lista de exercícios e prova.

Os estudantes demonstraram maior interesse pelas aulas, pois ficaram envolvidos com as atividades que exigiam diálogo, investigação, discussões, argumentação e necessariamente revisão de conteúdos de outras disciplinas, ações desnecessárias, muitas vezes, ao utilizar-se de aulas expositivas e listas de exercícios. Isso demonstra que foram envolvidos no processo de ensino e aprendizagem, foram os protagonistas de seu aprendizado, desenvolveram habilidade específicas que o mundo do trabalho exige, como proatividade, comportamento investigativo, capacidade de trabalhar 
em equipe e discutir ideias, além de aplicar, treinar e fixar os conhecimentos adquiridos, ao longo do curso, em outras áreas do conhecimento.

A metodologia de desenvolvimento da atividade por "Projetos de trabalho" e a avaliação da aprendizagem com os mapas conceituais, deram à professora a possibilidade de conhecer o que os alunos já sabiam sobre o tema e assim direcionar melhor o novo conteúdo proporcionando aos estudantes uma forma diferente de externar o que aprenderam, considerando que não houve a preocupação com o certo ou errado, pois os mapas conceituais representam a estrutura cognitiva de cada indivíduo.

Comparando os mapas conceituais iniciais (dos estudantes) aos mapas conceituais criados após a aplicação da metodologia de "Projetos de trabalho", pode-se observar a apropriação e/ou ampliação de conceitos, assim como a compreensão dos significados dos conteúdos, relacionando-os aos seus conhecimentos prévios.

Acredita-se que será de extrema importância a utilização cada vez mais de metodologias de ensino que promovam a participação do aluno e integração dos conteúdos curriculares com os saberes individuais e coletivos, visando atender às novas demandas do mundo do trabalho e não somente do mercado de trabalho.

\section{REFERÊNCIAS}

BACICH, L.; MORAN. J. (Org.). Metodologias ativas para uma educação inovadora: uma abordagem téorico-prática. Porto Alegre: Penso, 2018, p. 160.

BACICH, L. Por que metodologias ativas na educação? Inovação na Educação. 2018. Disponível em: <POR QUE METODOLOGIAS ATIVAS NA EDUCAÇÃO? - Inovação na educação (lilianbacich.com)> Acesso em: 18 jun. 2019.

BENTO, Maria Cristina Marcelino; NETO, João Augusto Mattar; OLIVEIRA, Neide Aparecida Arruda de. Metodologias ativas e novas tecnologias: o uso do plickers como ferramenta de avaliação. In: CONGRESSO INTERNACIONAL ABED DE EDUCAÇÃO À DISTÂNCIA. 2017. p. 1-10. Disponível em: https://educere.bruc.com.br/CD2011/pdf/4692_2652.pdf. Acesso em: 18 jun. 2019

BRASIL_Conselho Nacional de Educação/Câmara de Educação Superior. Diretrizes Curriculares Nacionais do Curso de Graduação em Engenharia. Resolução no 2, de 24 de abril de 2019. Publicado no DOU em: 26/04/2019. Edição: 80. Seção: 1. Página: 43. Disponível em: dcn_engenharia_rces002_19.pdf (udesc.br). Acesso em: 21 jul. 2021

COELHO, Thuany. Alunos aprendem melhor com formas de estudo prazerosas. Metodologias ativas, como estudos de caso, liberam mais neurotransmissores, estimulam e dão mais prazer aos estudantes. ISSN 2359-5191. Ano: 46 - Edição No: 31 - Educação - Faculdade de Ciências Farmacêuticas, 2013. Disponível em:

http://www.usp.br/aun/antigo/exibir?id=5202\&ed=920\&f=30. Acesso em: 18 jun. 2019.

IFMSa. História. Disponível em: https://www.ifms.edu.br/acesso-ainformacao/institucional/historia. Acesso em: 02 jul. 2019

IFMSb. Institucional - Missão. Disponível em: https://www.ifms.edu.br/acesso-ainformacao/institucional/historia. Acesso em: 02 jul. 2019 
HERNÁNDEZ, F; VENTURA. A organização do currículo por projetos de trabalho - 0 conhecimento é um caleidoscópio. Artmed: 5 ed, Porto Alegre, 1998.

HERNÁNDEZ, Fernando. Cultura Visual, Mudança Educativa e Projeto de Trabalho. Artmed: 1 ed. Porto Alegre, 2000, 264p.

NOVAK, Joseph D.; CANAS, Alberto J. A Teoria Subjacente aos Mapas Conceituais e como elaborá-Ios e usá-Ios. Práxis Educativa, Ponta Grossa, v.5, n.1, p. 9-29 , jan.-jun. 2010. Disponível em: https://dialnet.unirioja.es/servlet/articulo?codigo=3251296. Acesso em: 02 de jul. de 2019

PRADO, Maria Elisabette Brisola Brito; ALMEIDA, Maria Elizabeth Bianconcini de (organizadoras). Elaboração de projetos: guia do cursista. - 1.ed. - Brasília: Ministério da Educação, Secretaria de Educação à Distância, 2009. 174p. Disponível em: http://www.virtual.ufc.br/cursouca/modulo_4_projetos/conteudo/GuiadoCursista.pdf

Acesso em: 21 de jul. de 2021

PRADO, Maria Elisabette Brisola Brito. Pedagogia de projetos: fundamentos e implicações. In: ALMEIDA, Maria Elizabeth Bianconcini de; MORAN, José Manuel (Org.). Integração das tecnologias na educação. Brasília: Ministério da Educação/SEED/TV Escola/Salto para o Futuro, 2005.

RIBEIRO, Luis Roberto de Camargo. Aprendizagem baseada em problemas (PBL) na educação em engenharia. Revista de Ensino de Engenharia, v. 27, n. 2, p. 23-32, 2008. Disponível em: http://cmq.esalq.usp.br/Philodendros/lib/exe/fetch.php?media=temas:pbl:ribeiro-2008-ensino-deengenharia.pdf. Acesso em: 21 jul. 2021

SENA, Marina Tizzot Borges da Cruz; FINATTI, Jussara Riva. O processo de ensino- aprendizagem a partir de projetos de trabalho em uma abordagem crítica. $X$ Congresso Nacional de Educação - EDUCERE. PUCPR, Curitiba, 2011, p. 2468.Disponível em: https://educere.bruc.com.br/CD2011/pdf/4692_2652.pdf. Acesso em: 18 jun. 2019

SILVA, João Batista da; SALES, Gilvandenys Leite; CASTRO, Juscileide Braga de. Gamificação como estratégia de aprendizagem ativa no ensino de Física. Rev. Bras. Ensino Fís. v.41, n.4, São Paulo, 2019. ISSN 1806-9126 [Online] http://dx.doi.org/10.1590/1806-9126-rbef-2018-0309

SILVA, Claudia Maria Bezerra; SANTOS, Edlamar Oliveira. Formação continuada do professor do ensino médio integrado: concepções e importância. Revista Brasileira da Educação Profissional e Tecnológica, v. 1, n. 18, p. 9281, 2020. Disponível em: http://www2.ifrn.edu.br/ojs/index.php/RBEPT/article/view/9281/pdf. Acesso em: 21 jul. 2021

VALENTE, José Armando. Tecnologias e educação a distância no ensino superior: uso de metodologias ativas na graduação. Trabalho \& Educação, v. 28, n. 1, p. 97-113, 2019. Disponível em: https://periodicos.ufmg.br/index.php/trabedu/article/view/9871. Acesso em: 21 jul. 2021.

Submissão: 04/06/2021

Aceito: 27/07/2021 